\title{
APRENDIZAGEM E MUDANÇA ORGANIZACIONAL EM UMA INSTITUIÇÃO DE ENSINO SUPERIOR EM ADMINISTRAÇÃO
}

\author{
Marco Antonio Batista da Silva \\ med.silva@uol.com.br \\ Universidade Nove de Julho - São Paulo, SP / Brasil \\ Nildes R. Pitombo Leite \\ nildespitombo@consensopg.com.br \\ Universidade Nove de Julho - São Paulo, SP / Brasil
}

Recebido em 30/11/2012

Aprovado em 08/05/2013

Disponibilizado em 01/04/2014

Avaliado pelo sistema double blind review

Revista Eletrônica de Administração

Editor: Luís Felipe Nascimento

ISSN 1413-2311 (versão on-line)

Editada pela Escola de Administração da Universidade Federal do Rio Grande do Sul.

Periodicidade: Quadrimestral

Sistema requerido: Adobe Acrobat Reader.

\section{RESUMO}

Esta pesquisa tem como objeto de estudo a aprendizagem organizacional em uma Instituição de Ensino Superior (IES) em Administração na cidade de São Paulo. Objetiva analisar a contribuição da aprendizagem organizacional para a mudança no processo de ensinoaprendizagem nessa IES. Para auxiliar na consecução desse objetivo, definiu-se como objetivos específicos: analisar o desenvolvimento do ciclo de construção do conhecimento; investigar o processo de aprendizagem da instituição; verificar a presença de fatores inibidores e de fatores facilitadores ao processo de aprendizagem na instituição; examinar a cultura de aprendizagem dentro da instituição; averiguar a existência de mudanças no processo de ensino-aprendizagem em decorrência da cultura de aprendizagem investigada. $\mathrm{O}$ tema foi tratado utilizando-se a abordagem de pesquisa qualitativa, a estratégia de estudo de caso e as técnicas, baseadas em pesquisas bibliográfica, empírica e documental, com entrevistas em profundidade, grupo focal e observação para levantamento de dados. $\mathrm{O}$ resultado encontrado indicou que a apropriação e geração de novos conhecimentos nos níveis do indivíduo, do grupo e da organização, envolvendo tanto a aprendizagem formal quanto a informal, podem estar presentes nas mudanças estabelecidas pela IES, quando favorecida pela formação de um contexto capacitante desenvolvido por essa IES, em uma dinâmica de reflexão e ação sobre os fatores que inibem e facilitam o processo de desenvolvimento dessas mudanças. Concluiu-se que a aprendizagem organizacional é um construto que necessita ser considerado pelas organizações que estão inseridas em um contexto de constantes mudanças. No entanto, é complexo e não pode ser esgotado à luz de uma única perspectiva teórica, e nem de um único campo, proporcionando aos pesquisadores um vasto campo de estudos para que se possam gerar contribuições úteis ao mundo organizacional. O mesmo é considerado para o constructo mudança organizacional, que faz com que as organizações e as instituições busquem formas de adequação ao ambiente. No caso estudado, as adequações são estabelecidas por processos que podem ser considerados desde uma pequena mudança em uma rotina ou em um procedimento, até uma grande transformação institucional. Esse 
Aprendizagem e mudança organizacional em uma Instituição de Ensino Superior em Administração

processo é facilitado quando se é estabelecida uma cultura de aprendizagem por parte da instituição.

Palavras-Chave: Aprendizagem Organizacional; Mudança Organizacional; Processo de Ensino-Aprendizgem; Instituição de Ensino Superior - IES.

\title{
LEARNING AND ORGANIZATIONAL CHANGE IN AN INSTITUTION OF HIGHER EDUCATION IN ADMINISTRATION
}

\begin{abstract}
The objective of this research is organizational learning in a Higher Education Institution (HEI) in Administration in Sao Paulo City. Objective is to analyze the contribution of organizational learning for change in the process of teaching-learning in this institution. To assist in achieving this objective, we defined the following objectives: to analyze the cycle development of knowledge construction, investigate the learning process of the institution; verify the presence of inhibiting factors and facilitating factors to the learning process at the institution; examine the culture of learning within the institution; investigate the existence of changes in the teaching-learning process as a result of the culture of learning investigated. The theme was treated using the qualitative research approach, strategy of case study and techniques, based on literature, empirical and documentary research, with in-depth interviews, focus groups and observation for data collection. The result found was that the ownership and generation of new knowledge at the individual, group and organizational level, involving both formal and informal learning, may be present in the changes established by the IES, when favored by the formation of an enabling context developed by the IES, in a dynamic of reflection and action about the factors that inhibit and facilitate the process of developing these changes. It was concluded that organizational learning is a construct that needs to be considered by organizations that are inserted in a context of constant change. However, it is complex, which can not be sold-out in the light of a theoretical perspective single, and not a single field, providing to researchers a wide field of studies that they may generate useful contributions to the organizational world. The same is considered to construct organizational change, which it makes with that the organizations and institutions seek ways to adapt to the environment. In the case studied, the adaptations are established by processes that can be considered from a small change in a routine or a procedure, until a large institutional transformation. This process is facilitated when it is established a culture of learning by the part of institution.
\end{abstract}

Keywords: Organizational Learning; Organizational Change; Teaching-Learning Process; Higher education institution - HEI.

\section{INTRODUÇÃO}

Desde a antiguidade, passando pela administração científica, o conhecimento tem sido objeto de discussão de diversos campos de estudos em ciência sociais como a filosofia, a sociologia, a psicologia, a economia, entre outros. Sendo assim, não poderia estar fora do âmbito organizacional regido também pela ciência social aplicada - a administração.

REAd | Porto Alegre - Edição 77 - № 1 - janeiro/abril 2014 - p. 195-224 
O estudo das organizações, nesse contexto no qual estão inseridas essas organizações em um mundo contemporâneo de negócios, tem destacado, desde a segunda metade do século $\mathrm{XX}$, a importância da aprendizagem organizacional para compreensão da dinâmica das mudanças organizacionais oriundas da criação ou da assimilação de novos conhecimentos. Desenvolvese, assim, uma discussão sobre a aprendizagem organizacional nas várias teorias dos estudos organizacionais. Nesses estudos, Antonello (2005, p.27), considerando os pontos comuns das abordagens teóricas, definiu a aprendizagem organizacional como:

um processo contínuo de apropriação e geração de novos conhecimentos nos níveis
individual, grupal e organizacional, envolvendo todas as formas de aprendizagem -
formais e informais - no contexto organizacional, alicerçado em uma dinâmica de
reflexão e ação sobre as situações-problema e voltado para o desenvolvimento de
competências gerenciais.

Diante dessa definição, considerou-se relevante o estudo da aprendizagem organizacional, dentro do universo de uma Instituição de Ensino Superior - IES, com recorte focado em Administração. A premissa que norteia a escolha dessa instituição é: por ser uma organização que busca promover a aprendizagem individual faz-se necessário entender como essa organização aprende e como esse aprendizado reflete as mudanças no processo de ensinoaprendizagem, contribuindo para o aperfeiçoamento da aprendizagem individual e criando um ciclo de desenvolvimento do conhecimento.

As discussões acerca de aprendizagem são amplas, desde a abordagem nos níveis individual, grupal e organizacional, bem como das dinâmicas de interação entre eles. Também vem ganhando cada vez mais enfoque, em um cenário atual marcado pela competitividade, atribuindo à aprendizagem organizacional uma característica de vantagem competitiva de valor intangível. Segundo Castro e Figueiredo (2005), já no início da segunda metade do século XX, as implicações das capacidades e competências de uma empresa em aperfeiçoar seu desempenho técnico-econômico já despertavam interesses dos pesquisadores, como Penrose, 1959; Hollander, 1965; Winter, 1982; Teece e Pisano, 1994. No entanto, em meados dos anos 90 surgiram, na literatura internacional, estudos da relação entre os processos de aprendizagem e acumulação de competências tecnológicas em empresas de economias emergentes. Com isso, pode-se observar a grande relevância desse tema a partir das referências bibliográficas propostas nesta pesquisa.

Buscando-se aprofundar a investigação acerca da influência da aprendizagem organizacional na mudança do processo de ensino aprendizagem, esta pesquisa procurou responder à questão de pesquisa: Como se dá a contribuição da aprendizagem organizacional para a mudança no REAd | Porto Alegre - Edição 77 - N 1 - janeiro/abril 2014 - p. 195-224 
Aprendizagem e mudança organizacional em uma Instituição de Ensino Superior em Administração

processo de ensino-aprendizagem em uma Instituição de Ensino Superior - IES em Administração? Dessa forma, o principal objetivo desta pesquisa foi analisar a contribuição da aprendizagem organizacional para a mudança no processo de ensino-aprendizagem em uma Instituição de Ensino Superior - IES em Administração. Para auxiliar a consecução desse objetivo, definiram-se como objetivos específicos: analisar o desenvolvimento do ciclo de construção do conhecimento; investigar o processo de aprendizagem da instituição; verificar a presença de fatores inibidores e de fatores facilitadores ao processo de aprendizagem na instituição; examinar a cultura de aprendizagem dentro da instituição; averiguar a existência de mudanças no processo de ensino-aprendizagem em decorrência da cultura de aprendizagem investigada.

O quadro teórico, no qual a pesquisa está inserida, inicialmente aborda o conceito de aprendizagem organizacional, tema central da discussão, em seu caráter multiparadigmático. Em seguida o conceito de mudança e transformação organizacional, por meio da evolução do paradigma da estabilidade para o da transformação. Por fim, a discussão acerca do conceito do processo de ensino-aprendizagem com foco no ensino superior.

\section{REFERENCIAL TEÓRICO}

Esta sessão apresenta um quadro teórico no qual a pesquisa está inserida. Inicialmente aborda o conceito de aprendizagem organizacional, tema central da discussão. Em seguida, o conceito de mudança e transformação organizacional, por meio da evolução do paradigma da estabilidade para o da transformação. Por fim, apresenta a discussão acerca do conceito do processo de ensino-aprendizagem com foco no ensino superior.

\subsection{Aprendizagem Organizacional}

As organizações presentes no atual contexto de complexidade e de instabilidade ambiental têm buscado, cada vez mais, adequar-se a esse ambiente. A aprendizagem organizacional aparece como forma de resposta a esse desafio. No entanto, os estudos sobre esse tema têm demonstrado tratar-se de um fenômeno complexo abordado por diversas perspectivas (ANTONELLO; GODOY 2010).

Duas abordagens de estudo emergiram, com maior ênfase, a partir dos anos 1980 conforme Prange (2001); Antonello (2005); Takahashi (2007); Leite e Aquino (2008): a da 
aprendizagem organizacional, como processo social (descritivo); e a da organização de aprendizagem, como processo técnico (prescritivo ou incremental). Bastos, Gondim e Loiola (2004, p. 221) apesar de não identificá-las como dois mundos isolados, pois exercem influências mútuas entre si, disseram que tais abordagens "revelam significativas diferenças que são fontes de tensão e geradoras de debates que animam o campo".

Não há consenso entre os estudiosos sobre a definição do termo aprendizagem organizacional bem como suas bases, principalmente, segundo Crossan, Lane e White (1999), pelo fato do conceito ter sido aplicado por diversos pesquisadores a diferentes domínios, como filosofia, psicologia, sociologia, economia, estratégia. Disso se depreende que, mesmo analisando o conceito de aprendizagem organizacional em um domínio específico, observa-se a inexistência de consenso que apresente uma definição única para o fenômeno.

Não obstante essa inexistência de consenso sobre a definição há, conforme Fiol e Lyles (1985), ampla aceitação da noção e da importância da aprendizagem organizacional no desempenho estratégico. Nesta pesquisa, adota-se a definição de aprendizagem organizacional elaborada por Antonello (2005), anteriormente citada. Antonello e Godoy (2010) desenvolveram um estudo sobre aprendizagem organizacional por meio de sete abordagens: psicológica, sociológica, antropológica, da ciência política, histórica, econômica e da ciência da administração. Esta pesquisa, no entanto, tomou como focos principais as duas primeiras, cujas perspectivas teóricas serão apresentadas nos quadros 1 e 2 .

Ao analisar a aprendizagem organizacional sob a lente, termo utilizado por Prange (2001), da perspectiva psicológica, Antonello e Godoy (2010) apresentaram, ainda, duas visões distintas para o tema: como analogia da aprendizagem individual e como processo que tem como base a aprendizagem individual. Tanto em uma dimensão quanto em outra, o papel da aprendizagem individual acaba recebendo destaque. A psicologia apresenta inúmeras teorias para explicar a aprendizagem individual e, mesmo não se constituindo tema desta pesquisa, é importante se observar a influência de duas grandes correntes que trazem implicações às teorias organizacionais, conforme Abbad e Borges-Andrade (2004): a comportamental e a cognitiva. Ambas as correntes, analisando a mudança, enfatizam, no entanto, aspectos diferentes do processo.

A teoria da ação, proposta por Chris Argyris e Donald Schön (1978, 1996), caracteriza-se como uma das mais importantes e seminais abordagens sobre aprendizagem organizacional. 
Aprendizagem e mudança organizacional em uma Instituição de Ensino Superior em Administração

Para esses autores, essa teoria tem como base a criação de relatos dos padrões pessoais, interpessoais e organizacionais que inibem o inquérito, a investigação, assim como os valores e pressupostos subjacentes que permitem às pessoas obterem informações, interpretá-las e testá-las de modo a fazerem inferências válidas sobre a concepção de causalidade. Como dito por Argyris (2000, p. 92), “as pessoas, coerentemente, agem com incoerência, inconscientes da contradição entre sua teoria esposada e sua teoria em uso, entre a maneira como pensam que estão agindo e o modo como efetivamente agem”. Segundo Valença (1997), Argyris e Schön destacaram a carência de conhecimento das pessoas de como elas são ineficazes, do quão são incongruentes suas ações, com algumas de suas teorias proclamadas e de que a inconsistência ou a incongruência de suas teorias em uso contribuem para sua ineficácia.

Quadro 1 - Abordagem teórica na Perspectiva da Psicologia

\begin{tabular}{|c|c|c|}
\hline \multicolumn{3}{|c|}{ Perspectiva da Psicologia } \\
\hline Processo / Autores & $\begin{array}{l}\text { Níveis / Forma de } \\
\text { aprendizagem }\end{array}$ & $\begin{array}{c}\text { Contexto / Fontes de } \\
\text { aprendizagem }\end{array}$ \\
\hline $\begin{array}{l}\text { Behaviorista: mudança no } \\
\text { comportamento. } \\
\text { Antonello e Godoy (2010) }\end{array}$ & $\begin{array}{l}\text { - Individual e organizacional. } \\
\text { - Por meio do processo de } \\
\text { informação. }\end{array}$ & $\begin{array}{l}\text { - Conhecimento reconhecido } \\
\text { como potencialmente útil para a } \\
\text { organização. }\end{array}$ \\
\hline $\begin{array}{l}\text { Cognitivista: criação do conhecimento. } \\
\text { Kolb (1984); } \\
\text { Abbad e Borges-Andrade (2004) }\end{array}$ & $\begin{array}{l}\text { - Individual como mola } \\
\text { propulsora da possibilidade da } \\
\text { aprendizagem organizacional. } \\
\text { - Por meio das experiências } \\
\text { subjetivas e objetivas; } \\
\text { - Por meio de um processo ativo } \\
\text { de interação. }\end{array}$ & $\begin{array}{l}\text { - Indivíduo interage com seu } \\
\text { ambiente. } \\
\text { - Obtém como resultado o } \\
\text { conhecimento; } \\
\text { - Transforma a experiência. }\end{array}$ \\
\hline $\begin{array}{c}\text { Teoria da ação: } \\
\text { Ciclo simples: criação de acertos ou } \\
\text { detecção de erros, com mudança de } \\
\text { ação. } \\
\text { Ciclo duplo: quando há mudança nos } \\
\text { valores tanto no nível individual quanto } \\
\text { organizacional. } \\
\text { Argyris e Schön (1978; 1996); Argyris } \\
\text { (2000); Valença (1997); Poell, Yorks e } \\
\text { Marsick (2009); Antonello e Godoy } \\
\text { (2010). }\end{array}$ & $\begin{array}{l}\text { - Aprendizagem organizacional } \\
\text { imbricada com o pensamento e } \\
\text { ação dos seus indivíduos, que } \\
\text { possuem, de forma nata, teorias } \\
\text { que norteiam suas ações. }\end{array}$ & $\begin{array}{c}\text { - Para que a aprendizagem } \\
\text { aconteça, a organização deve } \\
\text { desenvolver um ambiente de } \\
\text { confiança na interação entre seus } \\
\text { indivíduos. } \\
\text { - É necessário que os indivíduos } \\
\text { se desprendam do raciocínio } \\
\text { defensivo e desenvolvam o } \\
\text { raciocínio produtivo. }\end{array}$ \\
\hline $\begin{array}{c}\text { Espiral do conhecimento: } \\
\text { Socialização; Externalização; } \\
\text { Combinação; Internalização. } \\
\text { Nonaka et al (2000); Nonaka e } \\
\text { Takeuchi (1997); Krogh, Ichijo e } \\
\text { Nonaka (2001); Antonacopoulou e } \\
\text { Chiva (2007); Antonacopoulou (2006); } \\
\text { Leite e Aquino (2008). }\end{array}$ & $\begin{array}{l}\text { - O conhecimento é classificado } \\
\text { como tácito: pessoal, específico, } \\
\text { difícil de ser formulado e } \\
\text { comunicado, e como explícito: } \\
\text { transmissível em linguagem } \\
\text { formal e sistemática. }\end{array}$ & $\begin{array}{c}\text { - Contexto capacitante: intenção, } \\
\text { autonomia, caos criativo, } \\
\text { redundância e variedade de } \\
\text { requisitos. } \\
\text { - Lugar no qual o conhecimento é } \\
\text { compartilhado, criado e utilizado. } \\
\text { - Rede de interações determinada } \\
\text { pela confiança e pela solicitude. }\end{array}$ \\
\hline $\begin{array}{c}\text { Comunidades de práticas: } \\
\text { - Compartilhamento do conhecimento; } \\
\text { - Soluções de problemas; } \\
\text { - Desenvolvimento de experiências. } \\
\text { Souza-Silva e Schommer (2008); } \\
\text { Antonacopoulou (2006); }\end{array}$ & $\begin{array}{l}\text { - Produção ou transformação do } \\
\text { conhecimento; } \\
\text { - Por meio de sujeitos com e/ou } \\
\text { em atividade; } \\
\text { - Engajamento espontâneo, } \\
\text { informal e autogerenciável. }\end{array}$ & $\begin{array}{l}\text { - Contexto formado pela divisão } \\
\text { do trabalho, relação de poder, } \\
\text { cultura, ambiente de colaboração } \\
\text { e confiança, compartilhamento e } \\
\text { práticas comuns, tendo como } \\
\text { fonte de aprendizagem a }\end{array}$ \\
\hline
\end{tabular}

REAd | Porto Alegre - Edição 77 - N 1 - janeiro/abril 2014 - p. 195-224 
Marco Antonio Batista da Silva \& Nildes R. Pitombo Leite

\begin{tabular}{|c|c|c|}
\hline $\begin{array}{c}\text { Antonello (2005); Valença (1997); } \\
\text { Gerardi e Nicolini (2002); Casey } \\
\text { (2005). }\end{array}$ & linguagem e os artefatos. \\
\hline
\end{tabular}

Fonte: elaborado pelos autores

As organizações, segundo Nonaka et al (2000), são desafiadas a formular respostas para as questões que lhes são apresentadas pelo meio externo envolvendo-as, assim, em um esquema de contínua melhoria. O esforço conjunto empregado na solução de problemas, bem como o aprendizado que se apresenta como resultado deste esforço, é socializado pelo grupo de trabalho, acumulando conhecimento e desenvolvendo novas sistemáticas para o processo de criação do conhecimento. Esse processo, segundo Nonaka e Takeuchi (1997), está fundamentado nas dimensões epistemológica e ontológica que se articulam pela conversão do conhecimento e pelas condições capacitadoras.

A perspectiva baseada em comunidades de práticas é a abordagem definida por Souza-Silva e Schommer (2008) como um grupo de pessoas que se aglutinam entre si, colaborando reflexivamente, compartilhando conhecimentos, experiências e soluções de problemas relacionados às suas práticas, desenvolvendo, assim, seus repertórios de experiências. "A noção de comunidade de prática sugere que trabalho, aprendizagem e inovação não são atividades distintas. Em vez disso, estão intimamente ligados uns com os outros em uma prática local" (GHERARDI; NICOLINI, 2002, p.196). Essas definições apresentadas corroboram a de Valença (1997, p. 266), para quem comunidade de prática "é a reunião de profissionais que têm uma prática comum, dispostos a regularem sua prática de acordo com as mesmas normas de conduta pessoal, relacional, técnica e de proficiência operativa". Segundo Antonello e Godoy (2010), a abordagem baseada em práticas, preocupa-se com a produção ou transformação do conhecimento por meio de sujeitos com e/ou em atividade. Conforme Antonello (2005), a aprendizagem emerge da interação das pessoas em um contexto formado pela divisão do trabalho, relação de poder, linguagem, cultura, ambiente. Nesse contexto, as práticas organizacionais afetam significativamente a aprendizagem individual, de acordo com Antonacopoulou (2006), segundo a qual há três fatores que influenciam a aprendizagem na organização: o contexto de aprendizagem, as políticas de aprendizagem no trabalho e a identidade institucional da aprendizagem individual como reflexo da aprendizagem organizacional. Em linha, Casey (2005) afirmou que há influência tanto do grupo de trabalho e das interações sociais quanto dos procedimentos e regras para a aprendizagem.

O primeiro fator, o contextual, apresenta-se, segundo Antonacopoulou (2006), com uma complexidade que transcende o microambiente organizacional. O contexto deve receber 
Aprendizagem e mudança organizacional em uma Instituição de Ensino Superior em Administração

atenção em uma análise ambiental mais ampla, considerando forças endógenas e exógenas que afetam a aprendizagem do indivíduo no trabalho. Como segundo fator, a estrutura de poder e a política de aprendizagem aparecem como dimensões das perspectivas e motivações subjacentes à aprendizagem, bem como das tensões entre as prioridades individuais e organizacionais no processo de aprendizagem. Dessas tensões tem-se o terceiro elemento que é a busca de uma identidade institucional da aprendizagem individual refletindo a identidade profissional. Para a autora, a aprendizagem individual é moldada pelos fatores contextuais. Essas abordagens da psicologia social estão próximas da segunda perspectiva definida por Antonello e Godoy (2010): a aprendizagem vista pela lente da sociologia.

Quadro 2 - Abordagem teórica na perspectiva da Sociologia

\begin{tabular}{|c|c|c|}
\hline \multicolumn{3}{|c|}{ Perspectiva da Sociologia } \\
\hline Processo / Autores & $\begin{array}{c}\text { Níveis / Forma de } \\
\text { aprendizagem }\end{array}$ & $\begin{array}{c}\text { Contexto / Fontes de } \\
\text { aprendizagem }\end{array}$ \\
\hline $\begin{array}{l}\text { - Instituições sociais envolvendo } \\
\text { participação dos indivíduos em } \\
\text { atividades sociais e na reflexividade. } \\
\text { - Criação, assimilação, compartilhamento } \\
\text { e transmissão, dentro de um grupo, de } \\
\text { valores, crenças, sentimentos, artefatos, } \\
\text { símbolos, metáforas e rituais. } \\
\text { Casey (2005); Antonacopoulou e Chiva } \\
\text { (2007); Cook e Yanow (1996); Berger } \\
\text { e Luckmann (1985); Leite e Aquino } \\
\text { (2008); Akgün, Lynn e Byrne (2003). }\end{array}$ & $\begin{array}{l}\text { - Aprendizagem é descrita como } \\
\text { objeto cultural oriundo de } \\
\text { práticas do trabalho cultural; } \\
\text { - Origina-se na participação dos } \\
\text { indivíduos em atividades sociais; } \\
\text { - Separa o conteúdo e o objeto } \\
\text { do conhecimento; } \\
\text { - Busca a legitimação do } \\
\text { conhecimento; } \\
\text { - Por meio da linguagem, do } \\
\text { diálogo e do comprometimento. }\end{array}$ & $\begin{array}{l}\text { - Ambiente humano, com a } \\
\text { totalidade de suas formações } \\
\text { sócio-culturais e psicológicas, } \\
\text { compartilhamento dos } \\
\text { significados e interação comum. }\end{array}$ \\
\hline $\begin{array}{l}\text { - Processo político da aprendizagem, } \\
\text { como potencial de manter a } \\
\text { organização flexível e hábil para mudar } \\
\text { em um contexto de incertezas. } \\
\text { Antonacopoulou e Chiva (2007); } \\
\text { Akgün, Lynn e Byrne (2003). }\end{array}$ & $\begin{array}{c}\text { - Aprendizagem organizacional } \\
\text { como complexidade social, } \\
\text { consciente ou inconsciente; } \\
\text { - Foco no grupo e na } \\
\text { comunidade, ao invés de tentar } \\
\text { entender o processo cognitivo ou } \\
\text { as estruturas conceituais; } \\
\text { - Envolve processamento de } \\
\text { informação, habilidade cognitiva } \\
\text { e emoção. }\end{array}$ & $\begin{array}{l}\text { - Princípios da complexidade } \\
\text { social: esquemas-diversidade e } \\
\text { interação-interdependência. } \\
\text { - Componentes da cognição } \\
\text { social importantes para o } \\
\text { contexto da aprendizagem } \\
\text { organizacional: } \\
\text { aquisição/implementação/disse- } \\
\text { minação da informação, não } \\
\text { aprendizagem, pensamento, } \\
\text { inteligência, improvisação, } \\
\text { sensemaking, emoção e memória. }\end{array}$ \\
\hline
\end{tabular}

Fonte: elaborado pelos autores

Por essa lente, a aprendizagem é descrita como objeto cultural oriundo de práticas do trabalho cultural. O processo formado por instituições sociais, envolvendo relações sociais é descrito como aprendizagem social, originando-se na participação dos indivíduos em atividades sociais e na reflexividade, separando o conteúdo e o objeto do conhecimento (ANTONELLO; GODOY, 2010), corroborando Casey (2005, p.132) para quem "o processo e o resultado da aprendizagem individual são inerentemente sociais". Essa perspectiva social, sob a ótica de 
Antonacopoulou e Chiva (2007), busca explicar qual tipo de contexto social, com foco no grupo e na comunidade, é mais adequado à aprendizagem organizacional, ao invés de tentar entender o processo cognitivo ou as estruturas conceituais.

Essa abordagem também é defendida por Cook e Yanow (1996), que trouxeram o conceito de cultura, aplicado às organizações, como um grupo de valores, crenças, sentimentos, artefatos, símbolos, metáforas, rituais, que é criado, herdado, compartilhado e transmitido dentro de um grupo, distinguindo-o de outros. Esse conceito está em linha com Berger e Luckmann (1985, p.75) ao afirmarem que "os homens em conjunto produzem um ambiente humano, com a totalidade de suas formações socioculturais e psicológicas" e, quando o indivíduo reflete sobre sua experiência, procura ajustar os significados em uma estrutura consistente, aumentando essa tendência com o compartilhamento dos significados e com a interação comum. Em decorrência, buscam a legitimação do conhecimento que é definido "como um conjunto de verdades universalmente válidas sobre a realidade” (op. cit., p.93).

Diante do exposto, sobre o tema de aprendizagem organizacional, vê-se sua complexidade enquanto fenômeno que não pode ser entendido, em sua completude, à luz de uma única perspectiva. Segundo Argyris (1978), por exemplo, a compreensão do significado de aprendizagem organizacional não poderia ser esgotada em uma perspectiva isolada. Por sua vez, Weick e Westley (2009) apresentaram aprendizagem organizacional como um oximoro, em que os processos de aprender (desorganizar e aumentar a variedade) e de organizar (esquecer e reduzir a variedade) são considerados como processos antagônicos. Faz-se necessária, dessa forma, a investigação do tema sob a lente de diversas abordagens para a compreensão da contribuição da aprendizagem organizacional para o processo de mudança e transformação organizacional.

\subsection{Mudança e Transformação Organizacional}

Em uma análise do ambiente organizacional, constata-se que a realidade ambiental de hoje é diferente da que as organizações viviam há 50 anos. Como dito por Fischer (2002), as organizações vivenciavam, até a década de 70, o chamado paradigma da estabilidade, preconizando a perenidade e a permanência da organização no tempo e no espaço. O período regido por esse paradigma não negava a presença de mudanças, sutis e harmônicas, constantes nas organizações, cujas características da gestão abordavam o controle, a centralização, a limitação da abrangência da mudança e prazo reduzido para implementação das mudanças. 
Aprendizagem e mudança organizacional em uma Instituição de Ensino Superior em Administração

A partir da década de 70, segundo a autora, o modelo de gestão das organizações precisou ser revisto, em virtude das profundas alterações sociais, econômicas e políticas que começaram a afetar o mundo dos negócios. Assim, deu-se a substituição imperiosa do paradigma da estabilidade para o paradigma da transformação organizacional em que "as mudanças não estavam focadas em um elemento da organização, mas tinham um caráter multidimensional." (FISCHER, 2002, p. 150). Corroboraram essa abordagem, Souza, Vasconcelos e BorgesAndrade (2009, p.33) ao salientarem que a "mudança é uma característica de toda organização. É um fenômeno multidimensional devendo ser apreendido nos diversos níveis em que ocorre". Nesse novo paradigma, a gestão está voltada para o aperfeiçoamento contínuo e não para a estabilidade de padrões, regras ou normas.

Essa mudança de paradigma traz ao universo organizacional um grande desafio, que é encontrar um modelo de gestão adequado. Abrahamson (2006, p. 5) apresentou essa dificuldade quando descreveu as posições extremas em que as organizações podem adotar: ser avessa a mudanças ou ser viciada em mudanças. O autor ofereceu "uma fórmula para uma mudança sustentável - uma mudança repetida que não afeta a capacidade que possa promover mudanças repetidas".

Os dois paradigmas, descritos acima, abordam dois conceitos: mudança e transformação. Pode-se identificar, na conceituação filosófica, apresentada por Abbagnano (2003), que esses conceitos trazem, em si, a idéia de uma ação que acontece como um processo de realização, tanto de mudança, como um movimento da realização do que está em potência, quanto de transformação, como um conteúdo que consiste em possibilidades, mas que trazem, para sua realização, a exigência da formulação em símbolos.

As diferenças que se apresentam nos conceitos a partir daí são grandes, começando pela questão de que, no mundo corporativo atual, as mudanças ambientais estão ocorrendo cada vez mais rápidas, exigindo que as organizações se adaptem com a mesma rapidez a esse ambiente. Fala-se de um processo que não possibilita uma mudança profunda, mas uma mudança incremental. Há o movimento de um estado para outro, no entanto esse movimento não traz profundidade de realização. Quando se fala em transformação, refere-se a um movimento muito mais profundo e duradouro.

Profundo, pois trata de um processo que altera os valores, a maneira de pensar, os modelos mentais, segundo Senge (1999). Exige comprometimento nesse processo, ou seja, é necessário 
que haja o verdadeiro desejo consciente para que a transformação aconteça. Para Fischer (2002, p.154), “o processo de transformação organizacional deve se constituir um eixo gerador de mudanças organizacionais que guardem consistência entre si e estejam sempre voltadas para o desenvolvimento da competitividade interna da organização".

Diante do caráter multidimensional do conceito de mudança, Wood Jr. (2000) relembrado por Bastos; Santos (2007, p. 28) definiu mudança como "qualquer transformação de natureza estrutural, estratégica, cultural, tecnológica, humana ou de qualquer outro componente capaz de gerar impacto em partes ou no conjunto da organização". No entanto, para esta pesquisa adotou-se o conceito abrangente de mudança, proposto por Lima e Bressan (2003) reenfatizado por Souza, Vasconcelos; Borges-Andrade (2009, p. 34), como

[...] qualquer alteração, planejada ou não, nos componentes organizacionais -
pessoas, trabalho, estrutura formal, cultura - ou nas relações entre a organização e
seu ambiente, que possa ter conseqüências relevantes, de natureza positiva ou
negativa, para a eficiência, eficácia e/ou sustentabilidade organizacional.

Segundo Bastos e Santos (2007), com base nesse conceito, a mudança organizacional ocorre tanto no nível macro, quando aborda estruturas e arranjos institucionais, quanto no nível micro, abordando os indivíduos e suas interações. Souza, Vasconcelos e Borges-Andrade (2009, p. 34) caracterizaram a mudança organizacional, por meio da abordagem do comportamento organizacional, a partir de três níveis: micro - indivíduo, meso grupo/equipe e macro - organização e afirmam que "qualquer alteração que afete a organização pode ser considerada como sendo uma mudança”. Além dos níveis em que a mudança ocorre, o contexto se apresenta como um elemento importante.

De acordo com Leitão (2010), citando Zarifian (2001), o ambiente de mudança é caracterizado por elementos que podem ser provenientes tanto de demandas do ambiente externo quanto do ambiente interno, como situações imprevistas no ambiente de trabalho. Bastos e Santos (2007, p. 28), tratando da mudança organizacional, disseram que [...] "fatores de natureza política, cultural e ambiental, dentre outros, também interferem na sua definição e implementação". Essas interferências podem apresentar-se na forma de resistências internas às mudanças.

Segundo Souza, Vasconcelos e Borges-Andrade (2009), algumas mudanças alteram os níveis de lealdade, comprometimento, estresse dos empregados, influenciando no cinismo, satisfação e motivação. Dessa forma, pressupõe-se, conforme Leite e Prieto (2009, p. 20), a necessidade 
Aprendizagem e mudança organizacional em uma Instituição de Ensino Superior em Administração

de "mudança nos padrões culturais com implicações no processo de transformação". Essa mudança de padrões é facilitada quando há criação de um contexto favorável á mudança.

Ainda citando Bastos e Santos (2007), criar sentido sobre a mudança interfere nas resistências internas existentes. Nesse sentido, a criação de um contexto favorável deve passar pela eliminação do temor em relação à mudança. Destaca-se, assim, o que foi dito por Leite e Prieto (2009), acerca do papel da liderança na criação desse contexto por meio de apoio efetivo, clareza e comunicação da visão, coerência entre discurso e prática, enfrentamento e remoção dos obstáculos, dentre outros. Tal argumento foi corroborado por Leitão (2010, p. 253), referindo-se aos processos de mudança, quando afirmou que "a participação dos empregados nos processos é determinada pelas atitudes dos gestores frente à mudança".

Ainda segundo Bastos e Santos (2007), esse ambiente é desenvolvido por meio da formação das redes sociais caracterizadas por interações pautadas em comunicação, troca e ajuda mútua, podendo ultrapassar os limites físicos da organização. Essas redes, para os autores, podem ser formais, por meio de ligações sociais formais ou padronizadas, ou informais, aquelas nas quais as interações são voluntárias e não prescritas pela organização. $\mathrm{O}$ compartilhamento de significados atribuído à mudança, pelas redes pode afetar o ritmo e os resultados das mudanças. O contexto, dessa forma, favorecerá o processo de transformação.

O processo de transformação organizacional foi apresentado por Fischer (2002) em um modelo de quatro etapas: a auscultação que consiste no levantamento e análise de dados visando à caracterização dos processos de trabalho, fluxos de comunicação e interações entre os indivíduos; a concepção, como a etapa de transição entre a constatação de problemas e a construção de uma forma de conceber e implementar as mudanças; a disseminação que é caracterizada pela ampliação da participação, de forma gradativa, dos funcionários no processo de transformação organizacional; e, por fim, a sustentação que consiste em um conjunto de atividades visando efetuar o monitoramento e a avaliação do processo.

Nesse contexto de mudança do paradigma da estabilidade para o da transformação em que estão inseridas as organizações, encontram-se, também, as instituições de ensino superior, cujo eixo central, o processo de ensino-aprendizagem, tem sido influenciado, conforme será abordado a seguir. 


\subsection{Processo de Ensino-Aprendizagem}

O fenômeno chamado de globalização apresenta uma sociedade que está repensando seus valores e em transformação vertiginosa, (STACCIARINI; ESPERIDIÃO, 1999). Por sua vez, Andrade, D’Ávila e Oliveira (2004, p. 82), apresentaram uma nova fase de acumulação capitalista na qual "o conhecimento e a técnica ganham importância como insumo para a produção, ampliando as possibilidades de competitividade entre os países e organizações”.

Nesse contexto, segundo esses autores, a IES depara-se com um dos grandes desafios que é a formação e requalificação de profissionais para um mercado de trabalho em transformação, o que, segundo Stacciarini e Esperidião (1999) não torna mais possível se manterem os moldes tradicionais de ensino que deixaram de atender às necessidades do educando. Isso corrobora Silva Júnior (1996) ratificado por Andrade; D’Ávila e Oliveira (2004, p. 82) ao considerar a universidade lócus de produção do conhecimento e formação de recursos humanos vivendo o desafio de ampliação e diversificação de sua atuação para atender às demandas colocadas pela complexidade social. Corroborando tais ideias, Camargos, Camargos e Machado (2006, p.2) analisaram os desafios do mercado que exige cada vez mais um profissional com capacidade permanente de aprendizado e com novas habilidades e competências, atribuindo à IES papel fundamental na preparação e capacitação dessa força de trabalho. "Ao desempenhar esse papel, as IES têm de estar sempre atentas, por um lado, às exigências e demandas do mercado e, por outro, à percepção e preferências dos alunos quanto às condições e à qualidade do ensino que lhes está sendo oferecido".

Diante desse contexto, ainda segundo Stacciarini e Esperidião (1999), o processo de ensinoaprendizagem tem passado por uma transformação em seu conceito: de um ensino tradicional, centrado no professor, para um ensino centrado no indivíduo. O primeiro supõe que o indivíduo é incapaz de aprender, devendo ser conduzido, o que produz, dessa forma, um fator inibidor da criatividade, da iniciativa, da autorresponsabilidade e da autodireção e gera um aluno memorizador, passivo, sem preparo para desenvolver questões práticas. No segundo, em que o indivíduo é o centro da aprendizagem, enfatizam-se as relações interpessoais buscando-se o desenvolvimento dos interesses e desenvolvimento do aluno, "ensinar é dirigir e fazer crescer o outro. Facilitar a aprendizagem é criar condições para que o outro, a partir dele próprio aprenda e cresça." (HADDAD et al., 1993, p. 99).

Nessa perspectiva, Moreira (1997) apresentou o processo de ensino-aprendizagem como uma rede de relacionamentos composta por quatro elementos que exercem maior ou menor 
Aprendizagem e mudança organizacional em uma Instituição de Ensino Superior em Administração

influência no processo: professor, aluno, conteúdo e variáveis ambientais constituídas pelos recursos da IES.

As concepções pedagógicas como definição dos objetivos, organização dos conteúdos, as metodologias e estratégias de ensino-aprendizagem até os mecanismos de avaliação fazem parte do que Andrade, D’Ávila e Oliveira (2004) chamaram de arcabouço que sustenta esse processo. Segundo Demo (1998) o processo de ensino-aprendizagem sugere a expressão 'aprender a aprender', entendida como um desafio para a pesquisa, professores preparados, alunos motivados e estruturas e recursos adequados, no qual a atividade de ensinar e aprender ultrapassa a mera atividade de repassar saber.

Após a exposição teórica dos constructos processo de ensino-aprendizagem, mudança organizacional e aprendizagem organizacional, pode-se entender o processo de ensinoaprendizagem como um elemento central para as instituições de ensino superior. As alterações no ambiente em que essas instituições estão inseridas influenciam mudanças ou transformações nesse elemento e a aprendizagem organizacional se apresenta como um constructo que pode contribuir para esse processo de mudança.

\section{METODOLOGIA}

A escolha da metodologia descrita neste artigo tem como objetivo obter resposta à questão de pesquisa que seja pautada no rigor científico. Dessa forma, foi adotada a abordagem de pesquisa qualitativa que "atribui descrição detalhada do fenômeno e dos elementos que o envolvem, aos depoimentos dos atores sociais envolvidos, aos discursos, aos significados e aos contextos" (VIEIRA, 2004, p.15).

Utilizou-se o método fenomenológico que busca a essência básica ou o significado subentendido fundamental da experiência (CRESWELL, 2007) ou, segundo Vergara (2005) consiste no estudo daquilo que se manifesta como é. Busca o resgate dos significados atribuídos pelos sujeitos ao fenômeno sob investigação, sendo o relato dos próprios sujeitos a fonte essencial de dados.

Escolheu-se como estratégia de pesquisa o estudo de caso, que se caracteriza pela investigação, em profundidade, de um fenômeno por meio da utilização de múltiplas fontes de evidência (YIN, 2010). Como estratégias de coletas de dados, utilizaram-se pesquisas bibliográfica, 
documental, com entrevistas semiestruturadas em profundidade e grupo focal para levantamento de dados conforme Vieira (2004); Mason (1996); Moreira (2004); Godoy (2006); Eisenhardt (1989); Yin (2010); Gil (2009); Flick (2004); Creswell (2007); como estratégia de tratamento dos dados utilizou-se a análise de conteúdo orientado por Bardin (2010) e Vergara (2005).

O caso estudado é uma instituição privada de ensino superior, situada na cidade de São Paulo e que oferece o curso de Bacharelado em Administração, escolhido pelo critério de acessibilidade. Foi adotada nesta pesquisa, inicialmente, a abordagem dedutiva buscando-se o desenvolvimento de uma revisão da literatura relacionada à aprendizagem organizacional e à mudança, traçando um referencial dos principais autores internacionais e nacionais, com objetivo de servir como um mapa que colabore para o alcance da proposta de pesquisa.

Pautada nessa orientação, esta pesquisa, definiu como sujeitos das entrevistas: um diretor, dois coordenadores e nove professores da área de graduação do curso de bacharelado em Administração da Instituição de Ensino Superior (IES). O critério de seleção dos sujeitos da pesquisa foi por acessibilidade, buscando atender aos critérios de que os sujeitos tenham mais de 3 anos de trabalho na instituição; no caso dos professores, que atuassem em áreas distintas do saber. O registro das entrevistas foi feito por meio de gravação direta e anotações realizadas pelos pesquisadores durante o processo, sendo esses dados tratados por meio de transcrição das gravações para melhor condição de análise dos dados coletados.

Buscando-se atender aos princípios próprios da estratégia de estudo de caso, envolvendo diversas fontes de evidências para triangulação de dados que encorajem a coleta de informações de fontes diversas que visem corroborar o mesmo fato ou fenômeno, utilizou-se, após as entrevistas, o grupo focal, constituído por outros seis sujeitos, com os mesmos níveis adotados nas entrevistas. Foram convidadas 14 pessoas, 11 confirmaram presença, no entanto somente 6 efetivamente comparecerem. O registro foi feito por meio de gravação direta de áudio e vídeo, sendo esses dados tratados por meio de transcrição para melhor condição de análise, e anotações realizadas pelos pesquisadores durante o processo de observação da realização do grupo focal.

Como fonte de evidência documental, buscou-se tanto documentos da IES, como discursos do alto escalão organizacional; memorandos; relatórios internos e externos; e documentos administrativos, produzidos por pessoas que vivenciaram o evento estudado, chamados de 
Aprendizagem e mudança organizacional em uma Instituição de Ensino Superior em Administração

documentos primários. As fontes desses documentos foram tanto os arquivos da instituição quanto os disponibilizados pela internet. Procurou-se, ainda, utilizar-se da estratégia de coleta por observações que, segundo Yin (2010, p. 136), "servem ainda como outra fonte de evidência no estudo de caso" para encontrar dados que ajudem na realização da pesquisa.

A triangulação de dados, nesta pesquisa, mostrou a importância de não simplesmente se coletar dados por diversas fontes de evidência, mas realmente efetuar um cruzamento desses dados buscando-se um melhor entendimento do fenômeno estudado.

\section{ANÁLISE E DISCUSSÃO DOS DADOS}

Os dados coletados nesta pesquisa, por meio de entrevistas e grupo focal, foram analisados à luz das perspectivas da psicologia e da sociologia (ANTONELLO; GODOY, 2010), trazidas na fundamentação teórica.

No processo behaviorista, o conhecimento é identificado como fonte de aprendizagem quando reconhecido como potencialmente útil pelo processo de informação, e foi assim identificado em entrevista: “[...] no momento em que nós recebemos as informações, já tomamos as ações que temos que tomar, a partir dessas informações [...]" ou quando o entrevistado reconhece a utilização desse conhecimento para a instituição.

Na visão cognitivista, o nível da aprendizagem individual é considerado como propulsor da aprendizagem organizacional, por meio da transformação da experiência desse indivíduo interagindo com seu ambiente. Esses aspectos dessa visão foram expressos nos fragmentos, quando dito que a aprendizagem organizacional é iniciativa individual aproveitada pela instituição, bem como quando o entrevistado afirmou que “[...] essa relação interpessoal também é muito importante para o conhecimento [...]", atribuindo importância à interação dos indivíduos para realização do conhecimento.

A aprendizagem experiencial é desenvolvida pela relação dos professores com colegas, coordenadores, diretores, alunos, nas discussões formais ou informais. A aprendizagem organizacional apresenta-se como um processo de criação do conhecimento pautado na soma dos conhecimentos individuais que, por uma interação aberta estabelecida entre esses indivíduos, esse conhecimento avança para os níveis do grupo e da organização. 
Ao ser analisada a perspectiva da psicologia, considerando-se o processo de aprendizagem à luz da teoria da ação, são apresentados tanto elementos da aprendizagem de ciclo simples quanto da aprendizagem de ciclo duplo. Verificou-se, também, que os elementos apresentados por essa teoria para o desenvolvimento do ciclo de aprendizagem foram relatados pelos entrevistados: “[...] o erro é mesmo um forma de aprendizado [...]”; “[...] aquilo que eu fiz de errado me fez crescer [...]". Viu-se na fundamentação teórica que o erro se apresenta como fonte de aprendizagem.

Ainda pela teoria da ação, o erro é elemento de mudança, caracterizando aprendizagem de ciclo simples quando se fala de acertos e erros sem atribuir qualquer relação aos questionamentos dos valores subjacentes a essa ação. Nos dados empíricos pode-se evidenciar alinhamento a essa base teórica em falas dos entrevistados como: “[...] os erros são detectados quando o resultado final não aparece [...]", "[...] é preciso estar aberto o tempo todo para identificar, principalmente as falhas e não somente identificar, como corrigi-las [...]". A detecção e a mudança das falhas apresentam a mudança na ação ou no comportamento por meio de um único loop de feedback, sem mudança nos valores tanto do indivíduo, quanto da organização.

A aprendizagem de ciclo duplo no nível do indivíduo foi identificada quando o entrevistado disse: “[...] minha visão mudou quando eu passei a reconhecer a importância do meu papel frente às pessoas que eu ensino [...]”; “[...] amadureci, no sentido de poder me preocupar muito mais com a qualidade do que com a quantidade [...]”; "[...] receber o feedback de todos, alunos, professores, eu acho que foi um crescimento, para mim, inexplicável”.

Outro aspecto importante aqui analisado foi a caracterização dada pelos entrevistados do ambiente de interação estabelecido pela IES, identificando a confiança como elemento presente em todos os níveis. Pode-se verificar o estabelecimento desse ambiente de confiança nos dados extraídos das entrevistas: “[...] essa confiança é bastante grande [...]”; “[...] há confiança em cada profissional [...]”; “[...] há confiança da organização para conosco [...]”; "Confio nos profissionais que trabalham aqui [...]".

A análise feita quanto à presença do raciocínio defensivo e do cinismo no ambiente da IES evidenciou que a defensividade se apresenta como algo nato ao indivíduo e isso foi dito: "[...] a defensividade se apresenta, principalmente quando se é questionado em relação às próprias práticas, o ser humano é autodefensivo [...]”. No entanto, essa defensividade, no ambiente 
Aprendizagem e mudança organizacional em uma Instituição de Ensino Superior em Administração

organizacional, não se destaca como algo que venha comprometer significativamente o processo de aprendizagem, segundo dados da pesquisa. Fundamenta-se em frases ditas pelos entrevistados: “[...] essa defensividade não chega a prejudicar o outro. Isso eu nunca vi aqui [...]”; “[...] eu não consigo enxergar na IES, as pessoas que atuam com defensividade [...]”; “[...] eu vejo que existe uma postura defensiva, mas ela acaba sendo minimizada, porque há reflexão posterior e abertura maior que acaba fazendo com que nós tenhamos uma mudança de comportamento".

Segundo Argyris e Schön (1996; 1978), a presença das rotinas defensivas desenvolve, nos indivíduos, o comportamento de ignorar ou zombar de intenções positivas de mudanças, chamado, pelos autores, de cinismo. Como essas rotinas foram evidenciadas como fator não expressivo no ambiente de interação estabelecido na IES, a presença de atitudes cínicas não é desenvolvida de forma a comprometer o processo de aprendizagem na instituição, como se evidencia em fragmento de entrevista: “[...] não sei se pode ser ingenuidade minha, mas eu vejo aqui tudo muito transparente. Eu não consigo enxergar cinismo na IES [...]”.

Ainda na análise da teoria da ação, buscou-se identificar o alinhamento entre a teoria esposada e a teoria em uso. Quando os entrevistados foram levados a pensar sobre o alinhamento entre o que se diz (teoria esposada) e o que se pratica (teoria em uso), houve divergências nas respostas: “[...] Na minha visão, discurso e prática no nível da instituição são bem alinhados [...]"; "[...] a instituição é muito coerente. [...]"; "A instituição procura praticar, procura alinhar esse discurso à prática [...]”; “[...] minha avaliação em relação ao discurso, eu não diria que está totalmente ao contrário, mas nem sempre o que se fala se faz. [...]”; “[...] a teoria nem sempre é coerente com a prática. [...]".

Ainda na perspectiva da psicologia, a abordagem sociocultural desenvolve o modelo do espiral do conhecimento. Os desafios apresentados às organizações, segundo Nonaka et al (2000), exige que elas busquem respostas por meio de esforço conjunto para a solução de problemas, bem como para seu aprendizado. Esse processo é caracterizado pelos conhecimentos tácito e explicito que compõem o ciclo desse espiral, composto pelas fases da socialização, externalização, combinação e internalização, todas abrangendo os níveis individual, grupal e organizacional.

A existência desse ciclo na IES foi evidenciada nos fragmentos: “[...] quando o colega comenta sobre uma experiência dele [...] nós tiramos uma experiência disso e acabamos 
fazendo um benchmark para a aula [...]”. Nesse caso tem-se a socialização do conhecimento tácito, bem como a externalização, quando é criada uma proposta. A combinação acontece no compartilhamento dos planos de aulas entre os professores. A internalização apresenta-se quando os professores consideram essas práticas institucionalizadas como rotina, na qual "[...] as práticas são quase uniformes [...]", como dito por um entrevistado.

Nesse modelo, analisam-se os elementos formadores de um contexto capacitante para a aprendizagem, pelo estabelecimento de um ambiente de confiança e solicitude. A solicitude, assim como a confiança que já foi descrita, foi caracterizada pelos entrevistados como uma característica do contexto de interação na IES, evidenciado nos fragmentos: “[...] todos são muito solícitos dentro da instituição"; "solicitude é uma característica, um valor da organização [...]”; “[...] quando você precisa de auxílio, não tem uma pessoa que possa contar, tem trinta $[\ldots]$ ". Esse pensamento foi expresso, de forma geral, por todos os entrevistados, o que evidencia ser, a solicitude, um fator facilitador do processo de aprendizagem na IES.

Além desse modelo de espiral do conhecimento, a abordagem sociocultural apresenta o de comunidade de práticas que destaca a perspectiva da construção social, que se preocupa com a produção ou transformação do conhecimento, por meio de sujeitos com e/ou em atividade, conforme destacado por Antonello e Godoy (2010).

A análise dos dados pela abordagem das comunidades de práticas é caracterizada pelos pontos relatados pelos entrevistados que evidenciaram o contexto da IES como favorável ao estabelecimento de comunidades de práticas: “[...] tem vários grupos na IES bem fechados, não hermeticamente fechados, mas fechados no sentido de fazer trocas de conhecimento. Grupos como finanças, grupo de matemática [...]”; “[...] aqui na IES, os professores novos que entram são muito abraçados e acolhidos pelos professores antigos [...]”.

O engajamento foi evidenciado, enquanto espontâneo, informal e autogerenciável, quando os entrevistados afirmaram: “as discussões entre nós professores são muito informais, geram um despertar para o conhecimento [...]”; "[...] tem a possibilidade de levar assuntos acadêmicos para um café fora da instituição [...]".

A segunda perspectiva analisada foi a da sociologia. A aprendizagem é vista, sob essa lente, como objeto cultural, fruto da participação dos indivíduos em atividades sociais. Diálogo, linguagem e comprometimento são identificados como fontes de aprendizagem. Esses elementos também se manifestam nos significados extraídos das entrevistas: “[...] o diálogo é 
Aprendizagem e mudança organizacional em uma Instituição de Ensino Superior em Administração

a ferramenta essencial para colaborar com o aprendizado, crescimento e evolução [...]”; “[...] todos que são professores têm comprometimento com o processo de ensino-aprendizagem, acho que sem exceção [...]”; “[...] a grande maioria dos indivíduos se compromete com a organização [...]".

Os principais valores organizacionais, elementos caracterizadores de uma cultura de aprendizagem, explicitados pelos sujeitos da pesquisa são descritos como a preocupação com a transformação do indivíduo: “[...] essa preocupação é eminente, é muito forte de verificar se realmente está gerando alguma transformação no indivíduo [...]”. Nessa primeira parte da perspectiva sociológica o processo de aprendizagem se dá por instituições sociais, com criação, assimilação, compartilhamento e transmissão do conhecimento, inseridos em um grupo de valores.

O contexto da complexidade social foi apresentado quando os entrevistados afirmaram: "[...] o conhecimento não é alinhado, porque você tem um profissional de mercado e um profissional acadêmico lecionando até a mesma disciplina e não há o alinhamento dessas duas questões [...]"; “[...] foram institucionalizadas em face de normas, procedimentos escritos, formais e reuniões de informações [...]”. Identificou-se inter-relação esquema-diversidade. Os componentes da cognição social foram analisados pelos relatos dos indivíduos entrevistados, a exemplo de: “[...] nós podemos, sabendo dessa cultura, identificar qual é nossa posição $[\ldots] "$.

A categoria pensamento, como um processo de inquérito, de geração de novas idéias para solução de problemas, foi analisada com base no fragmento: “[...] quando a IES se remete a olhar para si e verificar quais foram os prejuízos com esses erros e daí extrair uma nova prática, um novo modo de pensar, uma nova linha de atuação [...]”. Depreende-se que os conceitos estabelecidos pela perspectiva da Sociologia contribuem para o entendimento do processo de aprendizagem presente na IES.

Ao analisar o conteúdo das entrevistas, pode-se evidenciar a presença de elementos das duas perspectivas descritas por Antonello e Godoy (2010). Buscou-se confirmar as evidências encontradas nas entrevistas individuais, por meio da realização de um grupo focal. A análise e discussão dos dados coletados nesse grupo são apresentadas, seguindo o mesmo critério de tratamento e análise dos dados das entrevistas individuais. 
As bases teóricas da perspectiva da psicologia foram evidenciadas nesse grupo. Pôde-se constatar a associação da aprendizagem à questão comportamental, quando os integrantes afirmaram que a reflexão sobre a aprendizagem contribui "[...] para reforçar o comportamento". Ao mesmo tempo, a interação foi conceituada como fonte de aprendizagem em significados extraídos: “[...] o conhecimento é construído na interação [...]”; “[...] esse processo de construção de conhecimento se dá pelas relações [...]”; “[...] na sala dos professores, por exemplo, parece uma teia [...]". Todos esses fragmentos afirmaram a existência de indícios de uma cultura de aprendizagem na IES, bem como de fatores que indicam comunidades de práticas estabelecidas.

O ambiente estabelecido pela IES foi descrito como adequado ao compartilhamento do conhecimento, caracterizado por autonomia, solicitude e confiança: “[...] nós temos liberdade de construir [...]”; "[...] essa acolhida que nós temos é diferenciada, entre nós existe esse carinho e esse compartilhamento".

Evidenciaram-se, ainda, fontes formais e informais, conhecimento tácito e explícito, teoria e prática como elementos necessários para a construção do conhecimento: "[...] não dá para falar em aprendizagem somente por conteúdo, normas ou regras, mas pelo exemplo [...]”; “[...] a construção do conhecimento se dá pela questão técnica, obviamente, pois você não vai falar do que não conhece [...]”. Assim como nas entrevistas individuais, no grupo focal a perspectiva da psicologia apresenta-se como uma abordagem presente nas relações estabelecidas na IES estudada.

Pela perspectiva da sociologia, o processo de construção do conhecimento acontece pela interação do indivíduo com os ambientes interno e externo. O conceito do sensemaking como fonte de aprendizagem foi evidenciado quando uma professora do grupo disse que "identificação, significado, sentido, sintonia entre o que se acredita, conhece e domina são essenciais para a construção do conhecimento". A emoção foi expressa na fala de uma professora, se referindo ao processo de construção de conhecimento: "aqui na instituição é muito mais o perceber, o sentir" como fonte de aprendizagem.

A complexidade expressa no esquema-diversidade foi evidenciada no grupo focal quando se considerado por um integrante que "o processo de aprendizagem não se dá em situações favoráveis, muitas vezes a situação desfavorável é um grande fator de aprendizagem”. 
Aprendizagem e mudança organizacional em uma Instituição de Ensino Superior em Administração

Acolhimento, confiança e reconhecimento do papel social da IES, valorização do colaborador são valores destacados pelo grupo como elementos presentes no contexto ambiental da IES.

Compartilhamento dos significados e interação comum, expressos por necessidade de observação do entorno do indivíduo e reflexividade, quando foi explicitada a necessidade de “[...] nos unirmos e perguntarmos o que podemos fazer melhor?" ou quando foi dito que "[...] precisamos nos colocar no lugar do outro para compreender a situação".

As incertezas foram tratadas como necessidade de atentar-se às demandas que o contexto ambiental apresenta, quando dito: “[...] as necessidades e exigências dos alunos que procuram um curso de bacharelado são diferentes dos que procuram um de tecnologia e, tanto os professores quanto a IES precisam ter habilidade e flexibilidade para adequar-se a elas". Evidenciaram-se, no grupo, os conceitos inseridos na perspectiva da sociologia, conforme mostrado na fundamentação teórica. Verifica-se que, de certa forma, as abordagens da psicologia e da sociologia estiveram presentes na discussão realizada pelos membros desse grupo, corroborando as entrevistas individuais.

Visando-se atender aos critérios metodológicos para triangulação de dados, buscaram-se evidências do fenômeno estudado por meio de análise de documentos, registros de arquivos e observação direta dos pesquisadores. Os dados, dessas coletas foram extraídos por meio da análise da transcrição do discurso da pró-reitoria, em sessão de abertura de evento da instituição; transcrição da entrevista dada pela pessoa responsável pelo departamento de avaliação da instituição; documento de análise do projeto pedagógico do curso de Administração; dados extraídos do site institucional; entrevista dada pela reitoria a um programa jornalístico de grande rede de televisão nacional. A análise dos dados coletados por essas fontes de evidência foi feita atentando-se aos objetivos específicos de investigar e analisar o processo de construção do conhecimento, bem como examinar a cultura de aprendizagem presente na IES.

O ciclo de construção do conhecimento na IES foi assim evidenciado por essas fontes de evidência: “[...] mais de 40 grupos formados por professores e alunos pesquisadores, todos eles certificados pelo Conselho Nacional de Pesquisa e Tecnologia (CNPq), cuja produção científica vem alcançando grande destaque no meio educacional [...]”; mantidos pela IES, esses grupos trabalham para a construção do conhecimento; “[...] a instituição investe em recursos tecnológicos a fim de facilitar a transmissão de informações”. 
A busca de socialização do conhecimento foi analisada nessas fontes de evidência e se constatou que “[...] a IES patrocinou cursos de Avaliação Institucional na UNB para um grupo de professores e gestores envolvidos com esse processo, que socializaram o curso com os demais professores dessa IES”. Além do processo de transmissão do conhecimento, evidencia-se um elemento importante que é a preocupação com o desenvolvimento de uma cultura de aprendizagem. Essa cultura foi examinada pelos valores explicitados bem como pelo sonho da IES, constituindo-se elementos necessários para a criação de um contexto favorável ao processo de aprendizagem: "igualdade, qualidade, democracia e humanismo"; "democratizar o acesso de ensino de qualidade".

\section{CONSIDERAÇÕES FINAIS}

Considerando-se o processo de ensino-aprendizagem composto por professor, aluno, conteúdo e variáveis ambientais constituídas pelos recursos da IES, averigua-se que qualquer tipo de mudança em qualquer um desses elementos pode afetar o desenvolvimento do processo. Diante disso esta pesquisa buscou averiguar a existência das mudanças no processo de ensinoaprendizagem em decorrência da cultura de aprendizagem nessa IES.

Foram investigadas mudanças em todos os elementos: os alunos, a cada semestre se apresentam à IES com características, necessidades e comportamentos diferentes, oferecendo o desafio da complexidade social; os professores, como indivíduos inseridos em um ambiente de interação acadêmica e organizacional externo; a IES, proporcionando a esses profissionais novos conhecimentos teóricos e práticos, ocasionando, assim, mudanças em seu comportamento; o conteúdo, modificado por meio da produção do conhecimento estabelecido nesse ambiente de interação; as variáveis ambientais estabelecidas pela IES, que fazem parte do grupo de elementos no qual a complexidade da aprendizagem organizacional está focada nesta pesquisa.

Nos recursos estabelecidos pela IES, como elemento integrante do processo de ensinoaprendizagem em Administração, foram evidenciadas várias mudanças: criação de projeto de extensão, intitulado fórum de sustentabilidade e empreendedorismo; sistema de avaliação; oferta do curso de Bacharelado em Administração à distância; desenvolvimento do Programa interdisciplinar de Educação Tutorial, envolvendo duas áreas do saber; estrutura 
Aprendizagem e mudança organizacional em uma Instituição de Ensino Superior em Administração

departamental instituição; formação de núcleos docentes estruturantes; instituição de programa com vistas à formação de futuros professores.

Ao analisar-se o desenvolvimento do ciclo de construção do conhecimento, os resultados mostraram a produção por meio de um processo de interação nos níveis individual, grupal e organizacional, tendo como fontes para a construção desse conhecimento, fatores internos, como: recursos fornecidos pela IES, história da instituição e dos indivíduos, que criam um contexto capacitante; fatores externos, caracterizados por experiências e desafios apresentados aos indivíduos, ao grupo e/ou à instituição.

A investigação do processo de aprendizagem presente nessa IES deu-se pela constatação do estabelecimento de um contexto capacitante, que cria condições para desenvolvimento do ciclo de aprendizagem identificado como: criação, assimilação, transmissão e utilização do conhecimento. As bases desse processo são estabelecidas no nível institucional pela formação de um ambiente de confiança, solicitude, liberdade, autonomia, tolerância ao erro e sua utilização como fonte de aprendizagem; no nível do grupo pela caracterização de amizade, camaradagem, interesses comuns, compartilhamento de práticas; no nível do indivíduo, pela disposição e abertura às novas aprendizagens, às críticas; ausência, pelo menos de forma a comprometer o processo, do raciocínio defensivo e do cinismo. Em todos os níveis identificou-se a busca de melhoria, por meio de novas aprendizagens.

$\mathrm{Na}$ verificação dos fatores inibidores e facilitadores ao processo de aprendizagem, constataram-se como inibidores: tamanho da instituição, que muitas vezes interfere na comunicação; tempo, com que as demandas são apresentadas; velocidade com que as mudanças ocorrem, muitas vezes, faz com que os indivíduos não consigam a dedicação do tempo necessário para o processo poder ser realizado do modo desejado. Também foi destacada a falta de alguns recursos físicos que acabam dificultando o processo de aprendizagem. No nível dos indivíduos, verificaram-se, como inibidores: a presença de egos elevados; a relação de poder, mesmo que em situações isoladas, foi caracterizada como fator inibidor; a insegurança. Como fatores facilitadores destacaram-se: solicitude, como característica não só dos indivíduos, mas da instituição; ambiente de confiança, abertura para o diálogo, liberdade e autonomia; comunicação aberta. No nível dos indivíduos, caracterizamse comprometimento, camaradagem, amizade, compartilhamento. 
A cultura de aprendizagem dentro da IES foi examinada pelos valores e crenças que estão presentes na ação da IES, do grupo e do indivíduo. O alinhamento entre os valores desses níveis é caracterizado pela evolução e desenvolvimento nos resultados apresentados em seus processos de avaliação, nos quais o curso de Administração tem mostrado bom desempenho, o que caracteriza valorização pela qualidade do ensino. Do mesmo modo, pelo crescimento que o curso tem auferido, caracterizado pelo compromisso da IES de proporcionar acesso ao conhecimento e, com isso, mobilidade social e ascensão. Nos indivíduos esses valores estão presentes na valorização da aprendizagem como fonte de crescimento pessoal e social.

Conclui-se que aprendizagem organizacional é um constructo que necessita ser considerado pelas organizações inseridas em contexto de constantes mudanças. No entanto, é complexo, não pode ser esgotado à luz de uma única perspectiva teórica, propicia aos pesquisadores vasto campo de estudos capaz de gerar contribuições úteis ao mundo organizacional.

Pode-se afirmar que a mudança organizacional se apresenta como grande desafio a ser superado, apresentado pelo moderno dinamismo do ambiente organizacional, o que faz com que organizações e instituições busquem formas de adequação a esse ambiente. No caso estudado, as adequações são estabelecidas por processos, considerados desde uma pequena mudança em rotinas ou procedimentos, até uma grande transformação institucional. Esse processo é facilitado quando se é estabelecida uma cultura de aprendizagem.

Próprias da abordagem qualitativa, esta pesquisa apresenta limitações. Entretanto, a impossibilidade de generalização dos resultados não prejudica a sua relevância. Ademais, abre possibilidades para criação de novas agendas de pesquisas com outras IES, dentro e fora do estado investigado.

\section{REFERÊNCIAS}

ABBAD, G. S.; BORGES-ANDRADE, J. E. Aprendizagem Humana em Organizações de Trabalho. In: ZANELLI, J. C.; BORGES-ANDRADE, J. E. BASTOS, A. V. B. (Orgs.). Psicologia, Organizações e Trabalho no Brasil. Porto Alegre: Artmed, 2004.

ABBAGNANO, N. Dicionário de filosofia. São Paulo: Martins Fontes, 2003.

ABRAHAMSOM, E. Mudança organizacional: uma abordagem criativa, moderna e inovadora. São Paulo: M Books do Brasil Editora Ltda., 2006.

REAd | Porto Alegre - Edição 77 - N 1 - janeiro/abril 2014 - p. 195-224 
Aprendizagem e mudança organizacional em uma Instituição de Ensino Superior em Administração

AKGÜN, A. E.; LYNN, G. S.; BYRNE, J. C. Organizational Learning: a socio-cognitive framework. Human Relations, London, Thousand Oaks CA, v. 56, n.7, p. 839-868, 2003.

ANDRADE, C.; D’ÁVILA, C.; OLIVEIRA, F. Um olhar sobre a práxis pedagógica de mestrado profissional em Administração na Universidade Federal da Bahia. RBPG, v. 1, n. 2, p. 81-96, nov. 2004.

ANTONACOPOULOU, E.; CHIVA, R. The social complexity of organizational learning: the dynamics of learning and organizing. Management Learning, n. 38, p. 277-295, 2007.

ANTONACOPOULOU, E. The relationship between individual and organizational learning: new evidence from managerial learning practices. Management Learning, n. 34, p. 455-473, 2006.

ANTONELLO, C. S.; GODOY, A. S. A Encruzilhada da Aprendizagem Organizacional: uma visão Multiparadigmática. RAC, Curitiba, v. 14, n. 2, p. 310-332, Mar/Abr. 2010.

ANTONELLO, C. S. A metamorfose da aprendizagem organizacional: uma revisão crítica. In RUAS, R. L.; ANTONELLO, C. S.; BOFF, L. H. (Orgs.), Aprendizagem organizacional e competências. Porto Alegre: Artmed. p.12-33, 2005.

ARGYRIS, C. Ensinando pessoas inteligentes a aprender. In: Gestão do Conhecimento. HBR. Tradução: Afonso Celso da Cunha Serra. Rio de Janeiro: Editora Campus, 2000.

ARGYRIS, C. On Organizational Learning. 2nd. Ed. Oxford: Blackwell, 1999.

ARGYRIS, C.; SCHÖN, D. A. Organizational Learning II: theory, method, and practice. Reading, MA: AddisonWesley, 1996.

ARGYRIS, C.; SCHON, D. A. Organizational Learning: A Theory of Action Perspective. California: Addison-Wesley Publishing Company, 1978.

BARDIN, L. Análise de Conteúdo. Lisboa/Portugal: Edições 70, 5 ed., 2010.

BASTOS, A. V. B.; GONDIM, S. M. G.; LOIOLA, E. Aprendizagem organizacional versus organizações que aprendem: características e desafios que cercam essas duas abordagens de pesquisa. Revista de Administração - RAUSP, São Paulo. v. 39, n. 3, p. 220-230, 2004. 
BASTOS, A. V. B.; SANTOS, M. V. Redes sociais e informais e compartilhamento de significados sobre mudança organizacional. RAE, v. 47, n. 3, p. 27-39, jul/set 2007.

BERGER, P. L.; LUCKMANN, T. A Construção Social da Realidade: Tratado de Sociedade do Conhecimento. Tradução de Floriano de Souza Fernandes. Petrópolis: Vozes, 1985.

CAMARGOS, M. A.; CAMARGOS, M. C. S.; MACHADO, C. J. Análise das preferências de ensino de alunos de um curso superior de Administração em Minas Gerais. Revista de Gestão USP, São Paulo, v. 13, n. 2, p. 1-14, abril/junho 2006.

CASEY. A. Enhancing Individual and Organizational Learning: a sociological model. Management Learning, n. 36, p. 131-147, 2005.

COOK, S. D. N.; YANOW, D. Culture and Organizational Learning. In: COHEN, M. D.; SPROULL, L. S. Organizational Learning. London: Sage, 1996.

CRESWELL, J. W. Qualitative Inquiry and research design: choosing among five traditions. $2^{\mathrm{a}}$ ed. California. Thousand Oaks: Sage, 2007.

CROSSAN, M. M.; LANE, H. W.; WHITE, R. E. An Organizational Learning framework: from intuition to institution. The Academy of Management Review, v. 24, n. 3, p. 522-537, julho 1999.

DEMO, P. Desafios modernos da educação. Petrópolis: Vozes, 1998.

EISENHARDT, K. M.; SANTOS, F. M. Knowledge-based view: A new theory of strategy? In: A. PETTIGREW, A.; THOMAS, H.; WHITTINGTON, R., (Eds.), Handbook of strategy and management, $1^{\text {a }}$ ed. London, UK: Sage, p. 139-164, 2002.

EISENHARDT, K. M. Building Theories from Case Study Research. Academy of Management Review, v. 14, n. 4, p. 522-550, 1989.

FIOL, C. M.; LYLES, M. A. Organizational Learning. The Management Review, v. 10, n. 4, p. 803-814, Oct. 1985.

FISCHER, R. M. Mudança e transformação organizacional. In: FLEURY, M. T. L. et al. As Pessoas na Organização, p. 147-164. São Paulo: Editora Gente, 2002.

FLICK, U. Questões de Pesquisa. In: FLICK, U. Uma introdução à pesquisa qualitativa. 2 REAd | Porto Alegre - Edição 77 - Nº 1 - janeiro/abril 2014 - p. 195-224 
Aprendizagem e mudança organizacional em uma Instituição de Ensino Superior em Administração

ed. Porto Alegre: Bookman, p. 63-68, 2004.

GERARDI, S.; NICOLINI, D. Learing the Trade: A Culture of Safety in Pratice. In: Organization articles. Vol. 2. London. Thousand Oaks: Sage, p. 191-223, 2002.

GIL, A. C. Estudo de Caso: Fundamentação científica - subsídios para coleta e análise de dados - como redigir o relatório. São Paulo: Atlas, 2009.

GODOY, A. S. Estudo de caso qualitativo. In: GODOI, C. K.; BANDEIRA-DE-MELO, R.; SILVA, A. B. (Orgs.) Pesquisa qualitativa em estudos organizacionais - paradigmas, estratégias e métodos. São Paulo: Saraiva p. 115-146, 2006.

HADDAD et al. Enfermagem médico-cirúrgica: uma nova abordagem de ensino e sua avaliação pelo aluno. Rev. Latino-am. Enfermagem. Ribeirão Preto, v. 1, n. 2, p. 97-112, julho 1993.

KROGH, G. V.; ICHIJO, K.; NONAKA, I. Facilitando a criação de conhecimento: reinventando a empresa com o poder da inovação contínua. Rio de Janeiro: Campus, 2001.

KOLB, D. A. Experiential learning: experience as the source of learning and development. New Jersey: Prentice Hall, 1984.

LEITÃO, S. S. A importância do desenvolvimento de competências para a mudança organizacional. Gestão Contemporânea, Porto Alegre, ano 7, n. 7, jan/jun 2010, p. 245-268.

LEITE, N. R. P.; PRIETO, V. C. Gestão da mudança dos padrões culturais em direção ao paradigma da transformação: o caso da organização alfa. Produto \& Produção, v. 10, n.1, p. 19-37, fev. 2009.

LEITE, N. R. P.; AQUINO, L. M. A. P. Aprendizagem Organizacional, Liderança, Responsabilidade: fatores propulsores e inibidores. Pretexto, v. 9, n. 2, p. 117-142, abr/jun. 2008.

LIMA, S. M. V.; BRESSAN, C. L. Mudança organizacional: uma introdução. In LIMA, S. M. V. (Ed.). Mudança Organizacional - teoria e gestão. Rio de Janeiro: Editora FGV, p. 17-63, 2003.

MASON, J. Planning and designing qualitative research. In: MASON, J. Qualitative Researching. London: Sage, p. 9-19, 1996. 
MOREIRA, D. A. (Org.) Didática do ensino superior: técnica e tendência. São Paulo: Pioneira,

1997.

MOREIRA, D. A. Pesquisa em Administração: origens, usos e variantes do método fenomenológico. Revista de Administração e Inovação, v.1, p. 5-19. São Paulo: UNINOVE, 2004.

NONAKA, I.; TOYAMA, R.; NAGATA, A. A firm as a knowledge-creating entity: a new perspective on the theory of the firm. Industrial and Corporate Change. Oxford University Press Inc, v.9, n.1, pp. 1-20, 2000.

NONAKA, I.; TAKEUCHI, H. Criação de conhecimento na empresa: como as empresas japonesas geram a dinâmica da inovação. 2. ed. Rio de Janeiro: Campus, 1997.

POELL, R. F.; MARSICK, V. J. Organizing Project-Based Learning in Work Contexts: A crosscultural analysis of data from two projects. Adult Education Quarterly, v. 60, n. 1, p. 77-93, 2009.

PRANGE, C. Aprendizagem Organizacinal: desesperadamente em busca de teorias? In: Aprendizagem Organizacional e Organização de Aprendizagem - desenvolvimento na teoria e na prática. São Paulo: Atlas, 2001.

SENGE, P. M. et al. A dança das mudanças. Rio de Janeiro: Campus, 1999.

SILVA JÚNIOR, J. R. Tendências do ensino superior diante da atual reestruturação do processo produtivo no Brasil. In: CATANI, A. (org.). A universidade na América Latina: tendências e perspectivas. São Paulo: Cortez, 1996, p. 11-33.

SOUZA-SILVA, J. C.; SCHOMMER, P. C. A Pesquisa em Comunidades de Práticas: panorama atual e perspectivas futuras. O\&S, UFBA, v. 15, n. 44, p. 105-127, janeiro/março 2008.

SOUZA, M. G. S.; VASCONCELOS, L. C.; BORGES-ANDRADE, J. E. Pesquisando sobre Mudança nas Organizações: a produção brasileira em micro comportamento organizacional. Revista Psicologia: Organizações e Trabalho, v. 9, n. 2, p. 32-46, jul-dez 2009.

STACCIARINI, J. M. R.; ESPERIDIÃO, E. Repensando Estratégias de Ensino no Processo de Aprendizagem. Ver. Latino-am enfermagem. Ribeirão Preto, v. 7, n. 5, p. 59-66, dez./1999.

TAKAHASHI, A. R. W. Descortinando os processos da aprendizagem organizacional no REAd | Porto Alegre - Edição 77 - N 1 - janeiro/abril 2014 - p. 195-224 
Aprendizagem e mudança organizacional em uma Instituição de Ensino Superior em Administração

desenvolvimento de competências em instituições de ensino. 2007. 467 f. Tese (Doutorado em Administração) - Universidade de São Paulo - Faculdade de Economia, Administração e Contabilidade - Departamento de Administração, São Paulo, 2007.

VALENÇA, A. C. Eficácia Profissional: Obra em homenagem aos 23 anos da publicação de "Theory in Practice" de Chris Argyris e Donald Schön. Rio de Janeiro: Qualitymark, 1997.

VERGARA, S. C. Projetos e relatórios de pesquisa em administração. São Paulo: Atlas, 2005.

VIEIRA, M. M. F.; ZOUAIN, D. M. (Orgs.) Pesquisa Qualitativa em Administração. Rio de Janeiro: Editora FGV, 2004.

YIN, R. Estudo de Caso: Planejamento e Métodos. $4^{\text {a }}$ Ed. Porto Alegre: Bookman, 2010.

WEICK, K. E., WESTLEY, F. Aprendizagem Organizacional: Confirmando um Oximoro. In: CLEGG, S. R., HARDY, C., NORD, W. R. Handbook de Estudos Organizacionais: ação e análise organizacionais. Vol. 3, p 361-388. São Paulo: Atlas, 2009.

WOOD JR., T. Mudança organizacional: introdução ao tema. In: WOOD JR., T. (Org). Mudança organizacional: aprofundando temas atuais em administração de empresas. 2a ed. São Paulo: Atlas, p. 17-33, 2000. 